\title{
The Comparison of M-B CDI-K Short Form and K-ASQ as Screening Test for Language Development
}

\author{
Seong Woo Kim, MD, Ji Yong Kim, MD, Sang Yoon Lee, MD, Ha Ra Jeon, MD
}

Department of Physical Medicine and Rehabilitation, National Health Insurance Service Ilsan Hospital, Goyang, Korea

\begin{abstract}
Objective To investigate the usefulness of the communication domain in the Korean version of Ages and Stages Questionnaire (K-ASQ), and short form of the Korean version of MacArthur-Bates Communicative Development Inventories (M-B CDI-K), as screening tests for language developmental delay.

Methods Data was collected between April 2010 and December 2013, from children who visited either the Department of Physical Medicine and Rehabilitation or the Developmental Delay Clinic, presenting with language development delay as their chief complaint. All the children took the short form of M-B CDI-K and K-ASQ as screening tests, and received diagnostic language assessments including Sequenced Language Scale for Infants (SELSI) or Preschool Receptive-Expressive Language Scale (PRES).

Results A total of 206 children, mean age 29.7 months, were enrolled. The final diagnoses were developmental language disorder, global developmental delay, autism spectrum disorder, cerebral palsy, etc. The M-B CDI-K short form and the communication domain of the K-ASQ had $95.9 \%$ and $76.7 \%$ sensitivity, and $82.4 \%$ and $85.3 \%$ specificity, with regards to diagnostic language assessments. The M-B CDI-K short form showed higher negative predictive value and better accuracy than the communication domain of the K-ASQ.

Conclusion The screening ability of K-ASQ was not sufficient for children with language development delay, and the M-B CDI-K short form should be implemented for additional screening.
\end{abstract}

Keywords Language development disorder, Sensitivity and specificity, Accuracy

\section{INTRODUCTION}

Early identification of developmental delay is important for children with neurodevelopmental disorders, since early intervention can improve the children's developmental potential and minimize the sequelae of disabilities $[1,2]$. Numerous screening tests have been proposed and are currently being used for surveillance of develop-

Received November 20, 2015; Accepted May 9, 2016

Corresponding author: Ha Ra Jeon

Department of Physical Medicine and Rehabilitation, National Health Insurance Service Ilsan Hospital, 100 Ilsan-ro, Ilsandong-gu, Goyang 10444, Korea. Tel: +82-31-900-0970, Fax:+82-31-900-0028, E-mail: snoopyhara@hanmail.net

ORCID: Seong Woo Kim (http://orcid.org/0000-0002-1548-8147); Jiyong Kim (http://orcid.org/0000-0003-4693-8400); Sangyoon Lee (http://orcid. org/0000-0001-5943-8881); Ha Ra Jeon (http://orcid.org/0000-0002-4234-8086).

(c) This is an open-access article distributed under the terms of the Creative Commons Attribution Non-Commercial License (http://creativecommons.org/ licenses/by-nc/4.0) which permits unrestricted noncommercial use, distribution, and reproduction in any medium, provided the original work is properly cited. Copyright (C) 2016 by Korean Academy of Rehabilitation Medicine 
mental delay in children in their infancy and childhood. The National Health Screening Program for Infants and Children was established in Korea in 2007, and the program includes developmental screening using Korean version of Ages and Stages Questionnaire (K-ASQ) for all subjects [3].

The K-ASQ was adopted and standardized to Korean requirement from the ASQ, which was originally developed in the United States. The K-ASQ is a simple developmental screening tool for children aged between 4 months and 60 months in which the children's parent(s) or guardian(s) fill up a questionnaire. The questionnaire is comprised of five domains (communication, gross motor, fine motor, problem solving, and personal-social) with 6 questions in each domain. Appropriate questionnaire was chosen in accordance to the child's age, and the scores obtained from each domain were compared to the cutoff threshold of two standard deviations. If the score of any one of the five domains was below the threshold, the subject was diagnosed as having 'suspected developmental delay' [2].

The National Health Screening Program for Infants and Children screens neurodevelopmental disorders including developmental language disorders, which show isolated delay in the age-appropriate language skills [4]. Previous studies have reported the usefulness of KASQ for screening of children with developmental delay $[1,3,5]$. However, other studies have reported on the low sensitivity of ASQ for screening for language delays, thus resulting in many false-negatives [6].

Other screening instruments have been developed globally to identify children with suspected speech and language delay. Among them, the short form of the Korean version of MacArthur-Bates Communicative Development Inventories (M-B CDI-K) was readily available, and in our previous study, was verified as a reliable and valid screening test for language development delay in children [7].

This study was conducted to compare the communication domain of K-ASQ and the M-B CDI-K short form as a screening tool for developmental delay, particularly in the language domain.

\section{MATERIALS AND METHODS}

Between April 2010 and December 2013, children who visited to the Department of Physical Medicine and Rehabilitation or the Developmental Delay Clinic with a complaint of delayed language development, were enrolled in this study. The children underwent a physical and neurologic examination conducted by a physiatrist, and screening and diagnostic tests were done. We excluded children above the age of 35 months and those who did not complete essential tests including K-ASQ, M-B CDI$\mathrm{K}$, SELSI (Sequenced Language Scale for Infants), and PRES (Preschool Receptive-Expressive Language Scale). The study protocol was approved by the ethics committee of National Health Insurance Service Ilsan Hospital.

The M-B CDI-K short form is divided into two types: for children 9 to 17 months old, and the other is for children 18 to 35 months old. This test is composed of understanding score, expressing score, and playing with things or grammar score [7]. These scores were judged as either 'high risk' or 'non-high risk' by following the guideline. For the K-ASQ, age-matched questionnaire was chosen and conducted. The questionnaire scores were judged as 'pass' or 'fail', based on the comparison between the score of communication domain and cutoff value of less than two standard deviations.

As diagnostic language assessment, SELSI or PRES was conducted based on their developmental age. When PRES was not adequate for some children with severe language delay, it was substituted by SELSI. The language developmental delay was defined as language age below two standard deviations when using SELSI, and language age was at least 1 year behind normal when using PRES $[2,7,8,9]$.

In addition, children were evaluated with other diagnostic assessments such as the Bayley Scales of Infant Development II (BSID-II), the Korean Wechsler Preschool and Primary Scales of Intelligence (K-WPPSI), and Childhood Autism Rating Scale (CARS). Taking all the diagnostic tests and neurological examinations into consideration, the children were diagnostically classified as developmental language delay (DLD), global developmental delay (GDD), intellectual disability (ID), cerebral palsy (CP), or autistic spectrum disorder (ASD). DLD was diagnosed when developmental delay was confined to language, and cognition or motor and social function were not affected. GDD or ID was defined as the child having a significant delay in two or more developmental domains, including gross or fine motor, speech/language, 
cognitive, social/personal, and activities of daily living. ASD was diagnosed according to the Diagnostic and Statistical Manual of Mental Disorders (DSM)-IV.

\section{RESULTS}

This study included 206 children (142 male patients and 64 female patients), with mean age of 29.7 months (Table 1), of whom were diagnosed with DLD (79 children), GDD (or ID) (58 children), ASD (32 children), and CP (18 children). For the sake of convenience, the children who had only gross motor delay were categorized as $\mathrm{CP}$, and children with attention deficit hyperactivity disorder or childhood anxiety disorder who had no neurological or developmental abnormality were categorized as the normal development group (19 children).

Of the 206 children, 178 were tested with SELSI and the other 28 children were tested with PRES. Based on the SELSI or PRES results, 172 children were diagnosed with language development delay, whereas 34 children had normal language development. The two screening tests and the diagnostic language assessments were compared in these children. Of the 172 children with language de-

Table 1. General characteristics of subjects $(n=206)$

\begin{tabular}{|cc}
\hline \multicolumn{1}{c}{ Characteristic } & No. (\%) \\
\hline Gender & $142(68.9)$ \\
\hline Male & $64(31.1)$ \\
\hline Female & 29.7 \\
\hline Mean age (mo) & \\
\hline Diagnosis & $79(38.3)$ \\
\hline Developmental language disorder & $58(28.2)$ \\
\hline Global developmental delay & $32(15.5)$ \\
Autism spectrum disorder & $18(8.7)$ \\
\hline Cerebral palsy & $19(9.2)$ \\
\hline Normal developing children & \\
\hline
\end{tabular}

velopmental delay on diagnostic language tests, M-B CDI-K short form found 165 (95.9\%) children were high risk group, and the communication domain of K-ASQ found $132(76.7 \%)$ children to have failed the exam. Of the 34 normal children based on diagnostic language tests, M-B CDI-K short form and the communication domain of the K-ASQ results were similar (Table 2).

The sensitivity and specificity of the M-B CDI-K short form, where the diagnostic language assessments were

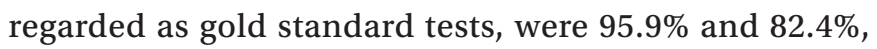
respectively. The sensitivity and specificity of the communication domain of the K-ASQ were $76.7 \%$ and $85.3 \%$ respectively, resulting in significantly higher sensitivity of the M-B CDI-K short form (Table 3). The positive predictive value and negative predictive value of the M-B CDI$\mathrm{K}$ short form were 0.96 and 0.82 , respectively. The positive predictive value and negative predictive value of the communication domain of the K-ASQ were 0.96 and 0.42 , respectively. The accuracies of those two screening tests were $94 \%$ for the M-B CDI-K short form, and $78 \%$ for the

Table 3. Comparison of results between M-B CDI-K SF and the communication domain of the K-ASQ

\begin{tabular}{lcc}
\hline & M-B CDI-K SF & $\begin{array}{c}\text { Communication } \\
\text { domain of the K-ASQ }\end{array}$ \\
\hline Sensitivity (\%) & 95.9 & 76.7 \\
Specificity (\%) & 82.4 & 85.3 \\
\hline PPV & 0.96 & 0.96 \\
NPV & 0.82 & 0.42 \\
Accuracy $^{\text {a) }}$ (\%) & 94.0 & 78.0 \\
\hline
\end{tabular}

M-B DCI-K SF, MacArthur-Bates Communicative Development Inventories short form; K-ASQ, Korean version of Ages and Stages Questionnaire; PPV, positive predictive value; NPV, negative predictive value; TP, true positive; $\mathrm{TN}$, true negative; FP, false positive; FN, false negative.

${ }^{\mathrm{a})}$ Accuracy $=\frac{\mathrm{TP}+\mathrm{TN}}{\mathrm{TP}+\mathrm{TN}+\mathrm{FP}+\mathrm{FN}}$

Table 2. Assessment results

\begin{tabular}{|c|c|c|c|c|}
\hline \multirow{2}{*}{ Diagnostic language tests } & \multicolumn{2}{|c|}{ M-B CDI-K SF } & \multicolumn{2}{|c|}{ Communication domain of the K-ASQ } \\
\hline & High risk & Non-high risk & Fail & Pass \\
\hline Normal & 6 & 28 & 5 & 29 \\
\hline Delay & 165 & 7 & 132 & 40 \\
\hline
\end{tabular}

M-B DCI-K SF, MacArthur-Bates Communicative Development Inventories short form; K-ASQ, Korean version of Ages and Stages Questionnaire. 
Table 4. Assessment results according to final diagnosis

\begin{tabular}{lccccc}
\hline \multirow{2}{*}{ Diagnosis } & \multicolumn{2}{c}{ M-B CDI-K SF } & & \multicolumn{2}{c}{ Communication domain of the K-ASQ } \\
\cline { 2 - 3 } \cline { 5 - 6 } & High risk & Non-high risk & & Fail & Pass \\
\hline DLD & 72 & 7 & 2 & 63 & 16 \\
GDD & 56 & 1 & & 30 & 18 \\
ASD & 31 & 8 & 30 & 2 \\
CP & 10 & 17 & 2 & 16 \\
Normal development & 2 & & & 2 & 17 \\
\hline
\end{tabular}

M-B CDI-K SF, MacArthur-Bates Communicative Development Inventories short form; K-ASQ, Korean version of Ages and Stages Questionnaire; DLD, developmental language disorder; GDD, global developmental delay; ASD, autism spectrum disorder; $\mathrm{CP}$, cerebral palsy.

Table 5. Comparison of sensitivity between M-B CDI-K SF and the communication domain of the K-ASQ based on the final diagnosis

\begin{tabular}{lcc}
\hline \multirow{2}{*}{ Diagnosis } & \multicolumn{2}{c}{ Sensitivity (\%) } \\
\cline { 2 - 3 } & $\begin{array}{c}\text { M-B } \\
\text { CDI-K SF }\end{array}$ & $\begin{array}{c}\text { Communication } \\
\text { domain of the K-ASQ }\end{array}$ \\
\hline DLD & 94.6 & 81.1 \\
GDD & 96.5 & 67.3 \\
ASD & 100 & 96.7 \\
CP & 88.9 & 22.2 \\
Normal development & 100 & 100 \\
\hline
\end{tabular}

M-B CDI-K SF, MacArthur-Bates Communicative Development Inventories short form; K-ASQ, Korean version of Ages and Stages Questionnaire; DLD, developmental language disorder; GDD, global developmental delay; ASD, autism spectrum disorder; $\mathrm{CP}$, cerebral palsy.

communication domain of the K-ASQ (Table 3).

The screening strength of the two screening tests according to final diagnosis were compared (Table 4). In DLD, GDD and CP groups, more children were screened out through M-B CDI-K short form than the communication domain of the K-ASQ. The sensitivity of M-B CDI-K short form was higher than the communication domain of the K-ASQ in DLD, GDD and CP groups (Table 5).

\section{DISCUSSION}

The prevalence of neurodevelopmental disorders in children is known to be about $16.8 \%$ [10]. It has been reported that $5 \%$ to $8 \%$ of preschool children are diagnosed with delayed language development, and $41 \%$ of children who visit the children development clinic have language delay as their chief complain [11-15].
According to data from the Korea National Statistical Office in 2014, only $1.0 \%$ of children with 'suspected developmental delay' had been found through the National Health Screening Program for Infants and Children. This number is much lower than expected, and all kinds of influencing factors should be analyzed. These could include factors of interpreting the screening test, and factors of the screening test itself. Therefore, this study focused to find whether the screening test (K-ASQ) is appropriate for detecting children with suspected developmental delay, particularly in the language domain.

Screening tests developed for early detection of language developmental delay include the Clinical Linguistic and Auditory Milestone Scale (CLAM), M-B CDI-K, M-B CDI-K short form, and SELSI [5,7,16,17]. The CLAM was developed by Dr. Capute in 1970s and standardized in the United States by Visintainer et al. [18]. However, till now, it has not been standardized in Korea. Only by professionally-trained speech therapists conduct SELSI, and it is an expensive and time consuming method. Reliability and validity of the MB-CDI-K have been validated since 2003, and the short form of MB-CDI-K has been developed and used since 2008 [17,19].

In Korea, the K-ASQ is used as a screening test for development in the National Health Screening Program for Infants and Children. The communication domain of the K-ASQ could be used for screening test of language developmental delay [20-22]. Although the K-ASQ has been reported to have high sensitivity and specificity as a screening test for developmental evaluation, no study has investigated sensitivity and specificity of the communication domain of K-ASQ. Therefore, the strength of this study lies in the fact that it provides sensitivity and specificity of the communication domain of the K-ASQ. 
Based on the results, the communication domain of the K-ASQ has a sensitivity (76.7\%) and specificity (85.3\%) that is sufficient to meet the criteria of useful screening test, which requires a sensitivity and specificity higher than $70 \%-80 \%$. However, compared to the M-B CDI-K short form that has $95.9 \%$ and $82.4 \%$ of sensitivity and specificity, respectively, the communication domain of the K-ASQ has lower sensitivity despite similar specificity. Therefore, the M-B CDI-K short form appears to be the more useful screening test for predicting language developmental delay than the K-ASQ. Moreover, the M-B CDI-K short form has a higher accuracy (94\%) compared to the communication domain of the K-ASQ (78\%), providing further evidence that M-B CDI-K short form is more efficient for screening language developmental delay than the communication domain of the K-ASQ.

The recently published systematic review for the US Preventive Services Task Force states that the M-B CDI and the Language Development Survey outperformed the ASQ communication domain [23]. In our study, M-B $\mathrm{CDI}-\mathrm{K}$ short form is a more powerful screening test in DLD, GDD and CP groups. This means that for the child who just passed the developmental screening test in the National Health Screening Program for Infants and Children, it is not possible to predict whether his or her language development was screened sufficiently.

The K-ASQ and the M-B CDI-K short form have the advantage that no professional training is required for the examiner, and it can be conducted within a short period of time with low cost. Both the K-ASQ and M-B CDI-K short form have already proven that they are reliable as well as valid $[7,17]$. Thus, they are ideal screening tests with various advantages for language development evaluation, though the M-B CDI-K short form has more advantages than the K-ASQ.

Despite many advantages, the M-B CDI-K short form is not popular in the hospital setting in Korea. Taking the diagnostic speech and language assessments at a hospital is not easy because of the high costs and long waiting lists. If a physiatrist in an outpatient clinic could assess the screening test personally for the children with suspected language delay, it could be helpful to decide whether or not to take intervention.

Early diagnosis as well as early treatment in children with language developmental delay is crucial in optimizing outcome. Thus, it is important to select the children with language developmental delay as well as other neurodevelopmental disorders. K-ASQ is a good screening tool for general developmental delay. However, for the children with isolated language delay, the screening potential of K-ASQ might not be sufficient, and M-B CDI-K short form can be additionally implemented.

\section{CONFLICT OF INTEREST}

No potential conflict of interest relevant to this article was reported.

\section{REFERENCES}

1. Kim EY, Sung IK. The ages and stages questionnaire: screening for developmental delay in the setting of a pediatric outpatient clinic. Korean J Pediatr 2007;50:1061-6.

2. Kim SW, Han ZA, Jeon HR, Choi JY, Chung HJ, Kim YK, et al. Neurodevelopmental disorders of children screened by the infantile health promotion system. Ann Rehabil Med 2011;35:867-72.

3. Chung HJ, Eun BL, Kim HS, Kim JK, Shin SM, Lee JH, et al. The validity of Korean Ages and Stages Questionnaires (K-ASQ) in Korean infants and children. J Korean Child Neurol Soc 2014;22:1-11.

4. Shevell M, Majnemer A, Platt RW, Webster R, Birnbaum R. Developmental and functional outcomes in children with global developmental delay or developmental language impairment. Dev Med Child Neurol 2005;47:678-83.

5. Ga HY, Kwon JY. A comparison of the Korean-ages and stages questionnaires and denver developmental delay screening test. Ann Rehabil Med 2011;35:369-74.

6. Pae S, Yoon H, Gilkerson J, Lee H, Sung IK. Early language and communication screening: the sensitivity and specificity of the Korean-Age and Stage Questionnaires. Korean J Early Child Spec Educ 2015;15;16779.

7. Kim SW, Jeon HR, Park EJ, Kim HI, Jung DW, Woo MR. The usefulness of M-B CDI-K Short Form as screening test in children with language developmental delay. Ann Rehabil Med 2014;38:376-80.

8. Kim YT, Kim KH, Yoon HR, Kim HS. Sequenced language scale for infants (SELSI). 1st ed. Seoul: Special Education Publishing; 2003. 
9. Kim YT, Sung TJ, Lee YK. Preschool receptive-expressive language scale (PRES). 1st ed. Seoul: Seoul Community Rehabilitation Center; 2003.

10. Boyle CA, Boulet S, Schieve LA, Cohen RA, Blumberg SJ, Yeargin-Allsopp M, et al. Trends in the prevalence of developmental disabilities in US children, 19972008. Pediatrics 2011;127:1034-42.

11. Jang JH, Park ES, Park JH, Baek JH, Won YH, Rha DW. Clinical usefulness of capute developmental test as a screening test for detecting the language delay. J Korean Acad Rehabil Med 2010;34:544-9.

12. Randall D, Reynell J, Curwen M. A study of language development in a sample of 3 year old children. $\mathrm{Br} \mathrm{J}$ Disord Commun 1974;9:3-16.

13. Burden V, Stott CM, Forge J, Goodyer I. The Cambridge Language and Speech Project (CLASP). I . Detection of language difficulties at 36 to 39 months. Dev Med Child Neurol 1996;38:613-31.

14. Harel S, Greenstein Y, Kramer U, Yifat R, Samuel E, Nevo $Y$, et al. Clinical characteristics of children referred to a child development center for evaluation of speech, language, and communication disorders. Pediatr Neurol 1996;15:305-11.

15. Eun JJ, Lee HJ, Kim JK. Developmental profiles of preschool children with delayed language development. Korean J Pediatr 2014;57:363-9.

16. Rossman MJ, Hyman SL, Rorabaugh ML, Berlin LE, Allen MC, Modlin JF. The CAT/CLAMS assessment for early intervention services. Clinical Adaptive Test/
Clinical Linguistic and Auditory Milestone Scale. Clin Pediatr (Phila) 1994;33:404-9.

17. Pae S, Kwak K, Kim M, Lee H, Jung K. Short form versions of MacArthur-Bates Communicative Development Inventories - Korean (M-B CDI-K). J Korean Soc Speech Sci 2008;15:119-29.

18. Visintainer PF, Leppert M, Bennett A, Accardo PJ. Standardization of the Capute Scales: methods and results. J Child Neurol 2004;19:967-72.

19. Pae S. Validity and reliability of the Korean adaptation of MCDI. Korean J of Commun Disord 2003;8:1-14.

20. Frisk V, Montgomery L, Boychyn E, Young R, vanRyn E, McLachlan D, et al. Why screening Canadian preschoolers for language delays is more difficult than it should be. Infants Young Child 2009;22:290-308.

21. Guiberson M, Rodriguez BL. Measurement properties and classification accuracy of two spanish parent surveys of language development for preschool-age children. Am J Speech Lang Pathol 2010;19:225-37.

22. Guiberson M, Rodriguez BL, Dale PS. Classification accuracy of brief parent report measures of language development in Spanish-speaking toddlers. Lang Speech Hear Serv Sch 2011;42:536-49.

23. Berkman ND, Wallace I, Watson L, Coyne-Beasley $\mathrm{T}$, Cullen $\mathrm{K}$, Wood C, et al. Screening for speech and language delays and disorders in children age 5 years or younger: a systematic review for the U.S. Preventive Services Task Force. Rockville: Agency for Healthcare Research and Quality; 2015. 